\title{
Reclassification of Roseivirga seohaensis (Yoon et al. 2005) Lau et al. 2006 as a later synonym of Roseivirga ehrenbergii Nedashkovskaya et al. 2005 and emendation of the species description
}

Correspondence

Olga I. Nedashkovskaya

olganedashkovska@yahoo.com

\author{
Olga I. Nedashkovskaya, ${ }^{1}$ Seung Bum Kim, ${ }^{2}$ Anatoly M. Lysenko, ${ }^{3}$ \\ Nataliya I. Kalinovskaya ${ }^{1}$ and Valery V. Mikhailov ${ }^{1}$ \\ ${ }^{1}$ Pacific Institute of Bioorganic Chemistry of the Far-Eastern Branch of the Russian Academy of \\ Sciences, Pr. 100 Let Vladivostoku 159, 690022 Vladivostok, Russia \\ ${ }^{2}$ Department of Microbiology, School of Bioscience and Biotechnology, Chungnam National \\ University, 220 Gung-dong, Yusong, Daejon 305-764, Republic of Korea \\ ${ }^{3}$ Institute of Microbiology of the Russian Academy of Sciences, Pr. 60 Let October 7/2, \\ 117811 Moscow, Russia
}

The genus Roseivirga was proposed to accommodate Gramnegative, strictly aerobic, heterotrophic, pink-pigmented, non-motile marine bacteria that belong to the phylum Bacteroidetes (Nedashkovskaya et al., 2005a). The strains of the first two described species of the genus, Roseivirga ehrenbergii and Roseivirga echinicomitans, were isolated from the green alga Ulva fenestrata and from the sea urchin Strongylocentrotus intermedius, respectively (Nedashkovskaya et al., 2005a, b). Soon after the description of the second species of the genus Roseivirga, R. echinicomitans, was completed, Yoon et al. (2005) proposed a novel genus with the type species Marinicola seohaensis. A single strain of this species was found in a seawater sample from the Yellow Sea. The type strain of Marinicola seohaensis had a very close phylogenetic relationship with the recognized species of the genus Roseivirga, demonstrating 99.1-99.9\% $16 \mathrm{~S}$ rRNA gene sequence similarity. The sequence data and phenotypic characteristics of [Marinicola] seohaensis served as evidence for the suggestion of the placement of the genus Marinicola and the species Marinicola seohaensis in the genus Roseivirga and for the emended description of the genus Roseivirga (Nedashkovskaya et al., 2005b). However, a formal inclusion of [Marinicola] seohaensis in the genus Roseivirga as Roseivirga seohaensis was made by Lau et al. (2006), together with the description of an additional species of the genus, Roseivirga spongicola. Due to the very close phylogenetic distances and the absence of data from DNADNA reassociation experiments between $R$. seohaensis, $R$. ehrenbergii and R. echinicomitans, the true taxonomic status of $R$. seohaensis has not been fully established.
In this paper, we report the results of a study of the phylogenetic, genomic and phenotypic characteristics of species of the genus Roseivirga and suggest that $R$. seohaensis is a later synonym of $R$. ehrenbergii.

Genomic DNA extraction, PCR and sequencing of 16S rRNA gene were performed according to procedures described previously (Kim et al., 1998). The sequence data obtained were aligned with those of representative members of selected genera that belong to the phylum Bacteroidetes using PHYDIT version 3.2 (http://plaza. snu.ac.kr/ jchun/phydit/). Phylogenetic trees were inferred using suitable programs of the PHYLIP package (Felsenstein, 1993). Phylogenetic distances were calculated from the models of Jukes \& Cantor (1969) and the trees were constructed on the basis of the neighbour-joining (Saitou \& Nei, 1987) method. Phylogenetic trees were also constructed using the maximum-likelihood and maximum-parsimony methods (Felsenstein, 1993). Bootstrap analysis was performed with 1000 resampled datasets by using the SEQBOOT and CONSENSE programs of the PHYLIP package.

Phylogenetic analysis of the almost-complete 16S rRNA gene sequences of $R$. ehrenbergii $\mathrm{KMM} 6017^{\mathrm{T}}$ and $R$. echinicomitans $\mathrm{KMM} 6058^{\mathrm{T}}$ revealed that they formed distinct lineages within the genus Roseivirga with a $16 \mathrm{~S}$ rRNA gene sequence similarity of $99.1 \%$. R. seohaensis SW$152^{\mathrm{T}}$ clustered with these strains and displayed values of gene sequence similarity with its closest relatives, $R$. ehrenbergii $\mathrm{KMM} 6017^{\mathrm{T}}$ and $R$. echinicomitans KMM 
$6058^{\mathrm{T}}$, of 99.9 and $99.1 \%$, respectively (Fig. 1). $16 \mathrm{~S}$ rRNA gene sequence similarity between $R$. seohaensis SW-152 ${ }^{\mathrm{T}}$ and R. spongicola UST030701-084 $4^{\mathrm{T}}$ was $96 \%$.

DNA was isolated according to the method of Marmur (1961) and the DNA G $+C$ content was determined by using the thermal denaturation method (Marmur \& Doty, 1962). The values for the DNA G $+C$ contents of strains KMM $6017^{\mathrm{T}}$, SW $-152^{\mathrm{T}}$ and $\mathrm{KMM} 6058^{\mathrm{T}}$ obtained in this study were $41.3,40.7$ and $41.1 \mathrm{~mol} \%$, respectively. DNADNA hybridization experiments were performed using the method of De Ley et al. (1970). The DNA-DNA relatedness levels between $R$. seohaensis SW-152 $2^{\mathrm{T}}$ and $R$. ehrenbergii KMM $6017^{\mathrm{T}}$ and R. echinicomitans $\mathrm{KMM} 6058^{\mathrm{T}}$ were 91 and $52 \%$, respectively. From these results, it is clear that strains $\mathrm{SW}-152^{\mathrm{T}}$ and $\mathrm{KMM} 6017^{\mathrm{T}}$ belong to the same species according to the proposal of Wayne et al. (1987). Therefore, $R$. seohaensis is a later heterotypic synonym of $R$. ehrenbergii.

Phenotypic analysis was performed using methods described previously (Nedashkovskaya et al., 2003a, b). API 20E, API 20NE, API ZYM (bioMérieux) and Microlog GN2 plates (Biolog) were also used for physiological and biochemical analyses, with the tests performed according to the manufacturers' instructions, except that the inoculum was prepared by suspending cells in a $1.5 \% \mathrm{NaCl}$ solution.

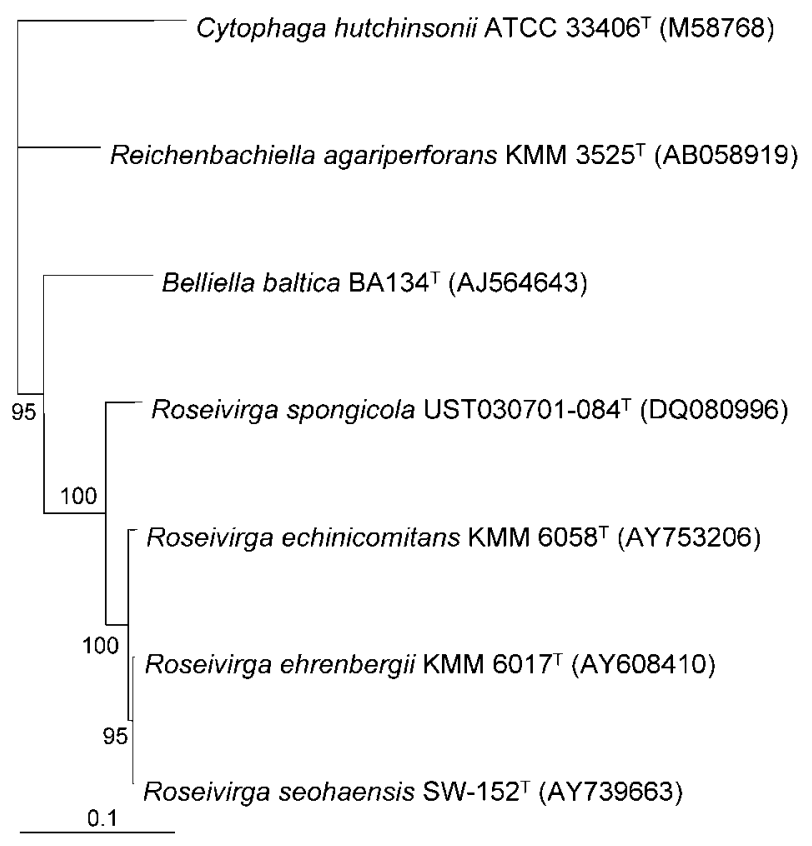

Fig. 1. Phylogenetic tree based on the 16S rRNA gene sequences of the type strains of the genus Roseivirga and selected other representative taxa belonging to the phylum Bacteroidetes. Numbers at nodes indicate levels of bootstrap support (\%) using 1000 resampled datasets. The same tree topology was also recovered from the maximum-likelihood and maximum-parsimony trees (not shown). Bar, 0.1 substitutions per nucleotide position.
Gliding motility was determined as described by Bowman (2000). For pigment characterization, strains $\mathrm{KMM} 6017^{\mathrm{T}}$, KMM $6058^{\mathrm{T}}$ and SW- $152^{\mathrm{T}}$ were grown on marine agar for $48 \mathrm{~h}$ at $28{ }^{\circ} \mathrm{C}$. The absorption spectrum of pigments extracted using 7:2 acetoin:methanol (v/v) was determined between 300 and $700 \mathrm{~nm}$ with a UV spectrophotometer (CE 7250/7000 series; CECIL).

The physiological, biochemical and morphological characteristics of the Roseivirga strains are given in the species description and in Table 1. The results of the phenotypic examination showed that there were many common traits between strain $\mathrm{SW}-152^{\mathrm{T}}$ and its closest relative, $R$. ehrenbergii (Table 1). Several features such as hydrolysis of aesculin and Tweens 40 and 80 and resistance to ampicillin and tetracycline were strain-dependent. The presence of flexirubin-type pigments was not found using the FautzReichenbach (Fautz \& Reichenbach, 1980) method or by using spectrophotometry in this study. Strain $\mathrm{SW}-152^{\mathrm{T}}$ was described as unable to hydrolyse gelatin, but in this study gelatinase production was shown to occur using the procedure described by Smibert \& Krieg (1994).

Consequently, on the basis of significant molecular, genotypic and phenotypic similarities between strain SW$152^{\mathrm{T}}$ and R. ehrenbergii presented in this study, we propose that Roseivirga seohaensis $\mathrm{SW}-152^{\mathrm{T}}$ is a later heterotypic synonym of Roseivirga ehrenbergii.

\section{Emended description of Roseivirga ehrenbergii}

Roseivirga ehrenbergii [eh.ren.ber'gi.i. N.L. gen. n. ehrenbergii of Ehrenberg, after the German biologist Christian Gottfried Ehrenberg (1795-1876), for his contribution to the development of microbiology].

The description is as given by Nedashkovskaya et al. (2005a) with the following additions. Cells range from 0.2 to $0.5 \mu \mathrm{m}$ in width and from 2.1. to $4.0 \mu \mathrm{m}$ in length. On marine agar, colonies are 1-4 $\mathrm{mm}$ in diameter and pinkorange-pigmented. Growth occurs at $4-40{ }^{\circ} \mathrm{C}$, at $\mathrm{pH} 5.5-$ 9.5 and with $1-8 \% \mathrm{NaCl}$. Optimal growth is observed at $23-30{ }^{\circ} \mathrm{C}$, at $\mathrm{pH} 7.0-8.0$ and with $2-3 \% \mathrm{NaCl}$. Hydrolysis of aesculin and Tweens 40, 60 and 80 is strain-dependent. Does not form acid from D-fructose, D-mannose, myoinositol or sorbitol. According to Microlog GN2 (Biolog), the type strain KMM $6017^{\mathrm{T}}$ utilizes glycogen, L-arabinose, methyl pyruvate, $\alpha$-ketoglutaric acid, glucuronamide, alaninamide, L-alanine, L-alanyl glycine, L-asparagine, Laspartic acid, L-glutamic acid, glycyl L-aspartic acid, Lhistidine, L-ornithine, L-proline, L-serine, L-threonine and putrescine but does not utilize $\alpha$-cyclodextrin, dextrin, $N$ acetyl-D-galactosamine, $\mathrm{N}$-acetyl-D-glucosamine, adonitol, D-arabitol, cellobiose, $i$-erythritol, D-fructose, L-fucose, Dgalactose, gentiobiose, $\alpha$-D-glucose, myo-inositol, $\alpha$-lactose, $\alpha$-D-lactose lactulose, maltose, D-mannitol, D-mannose, melibiose, methyl $\alpha$-D-glucoside, psicose, raffinose, Lrhamnose, D-sorbitol, sucrose, trehalose, turanose, xylitol, monomethyl succinate, acetic acid, cis-aconitic acid, citric acid, formic acid, D-galactonic acid, D-galacturonic acid, 
Table 1. Phenotypic characteristics that differentiate species of the genus Roseivirga

Taxa: 1, R. ehrenbergii KMM 6017 ${ }^{\mathrm{T}}$; 2, R. ehrenbergii SW-152 (=R. seohaensis $\left.\mathrm{SW}-152^{\mathrm{T}}\right)$; 3, R. echinicomitans KMM $6058^{\mathrm{T}} ; 4, R$. spongicola UST030701-084 ${ }^{\mathrm{T}}$. All taxa gave positive results for the following: respiratory metabolism; oxidase, catalase, esterase (C4), esterase lipase (C8), leucine arylamidase, valine arylamidase, $\alpha$ chymotrypsin, naphthol-AS-BI-phosphohydrolase, alkaline and acid phosphatase activities; growth at 1-8\% $\mathrm{NaCl}$ and at $31{ }^{\circ} \mathrm{C}$; and hydrolysis of gelatin. All strains gave negative results for the following: flexirubin production; $\mathrm{H}_{2} \mathrm{~S}$ and indole production; hydrolysis of agar, casein, starch, cellulose (CM-cellulose and filter paper) and chitin; acid production from L-arabinose, L-fucose, D-galactose, D-glucose, D-lactose, maltose, melibiose, L-rhamnose, L-sorbose, sucrose, cellobiose, raffinose, DL-xylose, $\mathrm{N}$-acetylglucosamine, glycerol, adonitol, inositol, mannitol, sorbitol, citrate; utilization of D-lactose, D-mannose, inositol, sorbitol and mannitol; $\alpha$-glucuronidase and $\alpha$-fucosidase activities; and susceptibility to kanamycin. + , Positive; - , negative.

\begin{tabular}{|c|c|c|c|c|}
\hline Characteristic & 1 & 2 & 3 & 4 \\
\hline Gliding motility & - & + & - & + \\
\hline Nitrate reduction & - & - & + & - \\
\hline Acetoin production & - & - & - & + \\
\hline Growth at $37^{\circ} \mathrm{C}$ & + & + & - & + \\
\hline \multicolumn{5}{|l|}{ Hydrolysis of: } \\
\hline DNA & + & + & - & + \\
\hline Tween 20 & + & + & - & + \\
\hline Tween 80 & - & + & - & + \\
\hline Acid from amygdalin & - & - & + & - \\
\hline \multicolumn{5}{|l|}{ Assimilation of: } \\
\hline Glucose, $\mathrm{N}$-acetylglucosamine, maltose, adipate & - & - & + & - \\
\hline \multicolumn{5}{|l|}{ Enzyme activity: } \\
\hline$\alpha$ - and $\beta$-Galactosidases & - & - & + & - \\
\hline$\beta$-Glucosidase & - & - & + & + \\
\hline Lipase (C14) & + & + & - & + \\
\hline \multicolumn{5}{|l|}{ Susceptibility to: } \\
\hline Ampicillin & + & - & + & - \\
\hline Benzylpenicillin, streptomycin & - & - & + & - \\
\hline Tetracycline & + & - & + & - \\
\hline DNA G $+\mathrm{C}$ content $(\mathrm{mol} \%)$ & 41.3 & 41.1 & 40.7 & 43.7 \\
\hline
\end{tabular}

D-gluconic acid, D-glucosaminic acid, D-glucuronic acid, $\alpha$-hydroxybutyric acid, $\beta$-hydroxybutyric acid, $\gamma$-hydroxybutyric acid, $p$-hydroxyphenylacetic acid, itaconic acid, $\alpha$ ketobutyric acid, $\alpha$-ketovaleric acid, DL-lactic acid, malonic acid, propionic acid, quinic acid, D-saccharic acid, sebacic acid, succinic acid, bromosuccinic acid, succinamic acid, Dalanine, glycyl L-glutamic acid, hydroxy-L-proline, Lleucine, L-phenylalanine, L-pyroglutamic acid, D-serine, DL-carnitine, $\gamma$-aminobutyric acid, urocanic acid, inosine, uridine, thymidine, phenylethylamine, 2-aminoethanol, 2,3-butanediol, glycerol, $\alpha$-DL-glycerol phosphate, glucose 1-phosphate or glucose 6-phosphate. Susceptible to carbenicillin, chloramphenicol, lincomycin and oleandomycin and resistant to benzylpenicillin, gentamicin, kanamycin, neomycin, polymixin B and streptomycin. Resistance to ampicillin and tetracycline is strain-dependent. Fatty acids accounting for more than $1.0 \%$ of the total are iso- $\mathrm{C}_{15: 1} \mathrm{G}(20.5-34.2 \%)$, iso- $\mathrm{C}_{15: 0}(24.0-33.5 \%)$, iso$\mathrm{C}_{17: 0} 3-\mathrm{OH}(7.7-11.2 \%)$, iso- $\mathrm{C}_{16: 0} 3-\mathrm{OH}(4.1-7.6 \%)$, iso$\mathrm{C}_{15: 0}$ 3-OH (3.0-5.6\%), iso- $\mathrm{C}_{13: 0}(3.2-5.2 \%)$, anteiso$\mathrm{C}_{15: 0}(2.4-4.5 \%), \mathrm{C}_{16: 0} 3-\mathrm{OH}(1.6-1.8 \%)$, anteiso- $\mathrm{C}_{15: 1}$ $(0-1.8 \%)$, iso- $\mathrm{C}_{16: 0}(1.1-1.2 \%), \mathrm{C}_{15: 0}(0.9-1.1 \%)$ and summed feature $3(1.7-4.8 \%)$, comprising $\mathrm{C}_{16: 1} \omega 7 c$ and/ or iso- $\mathrm{C}_{15: 0}$ 2-OH. Polar lipids of strain SW-152 are phosphatidylethanolamine, diphosphatidylglycerol, an unidentified phospholipid and a ninhydrin-positive lipid. The $\mathrm{G}+\mathrm{C}$ content of the DNA is $40-41 \mathrm{~mol} \%$.

The type strain, KMM $6017^{\mathrm{T}}\left(=\mathrm{KCTC} 12282^{\mathrm{T}}=\mathrm{LMG}\right.$ $22567^{\mathrm{T}}$ ), was isolated from the green alga Ulva fenestrata collected in Pallada Bay, Gulf of Peter the Great, East Sea.

A reference strain, SW-152 (=JCM 12600=KCTC 12312; the type strain of Roseivirga seohaensis), was isolated from a seawater sample in the Yellow Sea.

\section{Emended description of the genus Roseivirga Nedashkovskaya et al. 2005}

Roseivirga (Ro.se.i.vir'ga. L. adj. roseus, - $a$, -um pinkcoloured; L. fem. n. virga rod; N.L. fem. n. Roseivirga a pink-coloured and rod-shaped marine bacterium).

The description is as given by Nedashkovskaya et al. (2005a), with the following additions. Rod-shaped cells 
that can move by gliding. Arginine dihydrolase, lysine decarboxylase, ornithine decarboxylase and tryptophan deaminase-negative. The main cellular fatty acids are straight-chain unsaturated and branched-chain unsaturated fatty acids iso- $\mathrm{C}_{15: 1}$, iso- $\mathrm{C}_{15: 0}$, iso- $\mathrm{C}_{15: 0} 3-\mathrm{OH}$ and iso- $\mathrm{C}_{17: 0} 3-\mathrm{OH}$.

\section{Acknowledgements}

This research was supported by grant of the Presidium of the Far Eastern Branch of the Russian Academy of Sciences no. 06-III-A-06183, from the Presidium of the Russian Academy of Sciences 'Molecular and Cell Biology' and State Contract 'Leading Scientific Schools of RF' from the Federal Agency for Science and Innovations of the Russian Federation.

\section{References}

Bowman, J. P. (2000). Description of Cellulophaga algicola sp. nov., isolated from the surfaces of Antarctic algae, and reclassification of Cytophaga uliginosa (ZoBell and Upham 1944) Reichenbach 1989 as Cellulophaga uliginosa comb. nov. Int J Syst Evol Microbiol 50, 1861-1868.

De Ley, J., Cattoir, H. \& Reynaerts, A. (1970). The quantitative measurement of DNA hybridization from renaturation rates. Eur $J$ Biochem 12, 133-142.

Fautz, E. \& Reichenbach, H. (1980). A simple test for flexirubin-type pigments. FEMS Microbiol Lett 8, 87-91.

Felsenstein, J. (1993). PHYLIP (phylogenetic inference package), version 3.5c. Department of Genetic, University of Washington, Seattle, USA.

Jukes, T. H. \& Cantor, C. R. (1969). Evolution of protein molecules. In Mammalian Protein Metabolism, volume 3, pp. 21-213. Edited by H. N. Munro. New York: Academic Press.

Kim, S. B., Falconer, C., Williams, E. \& Goodfellow, M. (1998). Streptomyces thermocarboxydovorans sp. nov. and Streptomyces thermocarboxydus sp. nov., two moderately thermophilic carboxydotrophic species isolated from soil. Int J Syst Bacteriol 48, 59-68.

Lau, S. C. K., Tsoi, M. M. Y., Li, X., Plachotnikova, I., Dobretsov, S., Wu, M., Wong, P. K., Pawlik, J. R. \& Qian, P. Y. (2006). Description of Fabibacter halotolerans gen. nov., sp. nov. and Roseivirga spongicola sp. nov., and reclassification of [Marinicola] seohaensis as Roseivirga seohaensis comb. nov. Int J Syst Evol Microbiol 56, 1059-1065.

Marmur, J. (1961). A procedure for the isolation of deoxyribonucleic acid from microorganisms. J Mol Biol 3, 208-218.

Marmur, J. \& Doty, P. (1962). Determination of the base composition of deoxyribonucleic acid from its thermal denaturation temperature. J Mol Biol 5, 109-118.

Nedashkovskaya, O. I., Suzuki, M., Vysotskii, M. V. \& Mikhailov, V. V. (2003a). Reichenbachia agariperforans gen. nov., sp. nov., a novel marine bacterium in the Cytophaga-Flavobacterium-Bacteroides phylum. Int J Syst Evol Microbiol 53, 81-85.

Nedashkovskaya, O. I., Kim, S. B., Han, S. K., Lysenko, A. M., Rohde, M., Zhukova, N. V., Falsen, E., Frolova, G. M., Mikhailov, V. V. \& Bae, K. S. (2003b). Mesonia algae gen. nov., sp. nov., a novel marine bacterium of the family Flavobacteriaceae isolated from the green alga Acrosiphonia sonderi (Kütz) Kornm. Int J Syst Evol Microbiol 53, 1967-1971.

Nedashkovskaya, O. I., Kim, S. B., Lee, D. H., Lysenko, A. M., Shevchenko, L. S., Frolova, G. M., Mikhailov, V. V., Lee, K. H. \& Bae, K. S. (2005a). Roseivirga ehrenbergii gen. nov., sp. nov., a new marine bacterium of the phylum 'Bacteroidetes', isolated from the green alga Ulva fenestrata. Int J Syst Evol Microbiol 55, 231-234.

Nedashkovskaya, O. I., Kim, S. B., Lysenko, A. M., Park, M. S., Mikhailov, V. V., Bae, K. S. \& Park, H. Y. (2005b). Roseivirga echinicomitans sp. nov., a novel marine bacterium isolated from the sea urchin Strongylocentrotus intermedius, and emended description of the genus Roseivirga. Int J Syst Evol Microbiol 55, 1797-1800.

Saitou, N. \& Nei, M. (1987). The neighbor-joining method: a new method for reconstructing phylogenetic trees. Mol Biol Evol 4, 406-425.

Smibert, R. M. \& Krieg, N. R. (1994). Phenotypic characterization. In Methods for General and Molecular Bacteriology, pp. 607-654. Edited by P. Gerhardt et al. Washington, D.C.: American Society for Microbiology.

Wayne, L. G., Brenner, D. J., Colwell, R. R., Grimont, P. A. D., Kandler, O., Krichevsky, M. I., Moore, L. H., Moore, W. E. C., Murray, R. G. E. \& other authors (1987). International Committee on Systematic Bacteriology. Report of the ad hoc committee on reconciliation of approaches to bacterial systematics. Int J Syst Bacteriol 37, 463-464.

Yoon, J.-H., Kang, S.-J., Lee, C.-H. \& Oh, T.-K. (2005). Marinicola seohaensis gen. nov., sp. nov., isolated from sea water of the Yellow Sea, Korea. Int J Syst Evol Microbiol 55, 859-863. 